\title{
Empathy and Other Ways of Not Understanding: In Search of a Socially Transformative Relationality
}

\author{
Guy Smith
}

\section{Introduction}

In this paper I explore three unorthodox 'listening practices', each derived from the field of psychotherapy, and ask: what, if anything, might these practices contribute to society, if carried out beyond the consultation room? I first contextualise the project in terms of its relationship to Leo Bersani's work in his and Adam Phillips' book Intimacies (2008). ${ }^{1}$ Secondly, I outline each of the practices in turn, to give a felt, as well as theoretical, sense of each. I then proceed to consider the criticisms of standard forms of communication associated with the three practices. Fourthly, I consider where the theories associated with the practices clash - and here empathy emerges as the core matter - and plot a way out of this impasse. Lastly, I outline the effects of the practices therapeutically, and imagine how the practices, if taken up beyond the context of psychotherapy, might improve society.

\section{Context and Method}

This paper takes its cue from Leo Bersani and Adam Phillips' work Intimacies, which in turn takes up Michelle Foucault's call for 'new relational modes'. modes' may be defined simply as 'ways of relating' - i.e. to someone or something else.) Bersani, in his contribution to Intimacies, gives the following account of Foucault's 'call':

There is no solution easily recognizable as "political" to the political horrors [of human atrocities] [...] because no recognizably political solution can be durable without something approaching a mutation in our most intimate relational system. Foucault's call for "new relational modes" struck some of his readers as politically evasive; it seems to me, on the contrary, $[\ldots]$ an instance of political realism and a moral imperative. ${ }^{3}$

Bersani's response to Foucault's call is to develop (in theory) a new relational mode derived substantially from, yet for application beyond, psychoanalysis: 'I will be considering psychoanalysis as an inspiration for modes of exchange that can only take place outside of psychoanalysis'. ${ }^{4}$ In fact, he mourns that 'the new relational mode' of psychoanalysis 'is sequestered' in and by psychoanalysis-as-institution - 'the world

\footnotetext{
${ }^{1}$ Bersani, Leo and Adam Phillips. Intimacies. (Chicago: University of Chicago Press, 2008).

${ }^{2}$ Foucault, Michel. "Friendship as a Way of Life," in Foucault Live: Collected Interviews, 1961-1984, ed. Sylvère Lotringer, trans. Lysa Hochroth and John Johnson (New York: Semiotext(e), 1996), 310.

${ }^{3}$ Bersani and Phillips, Intimacies, 76-77.

${ }^{4}$ Ibid., 4.
} 
[...] excluded from it'. ${ }^{5}$ And he hence goes as far as to suggest that 'psychoanalysis must be sacrificed for its own invaluable lesson' ${ }^{6}$

While I accept Bersani's argument, and find myself galvanized by his project, I take issue with his unwarranted narrowness of vision as regards psychotherapy. Why does he fail to consider the enormous range of unconventional relational modes operative across the psychotherapies? Why does he privilege psychoanalysis - and a very specific version of psychoanalysis at that - to the exclusion of all other approaches?

To address that lack in Bersani's project, this paper casts a wider net, to consider two quite different takes on psychoanalytical practice, along with a little-known method from 'Biodynamic Psychotherapy'. While this still represents a small sample of the thousands of forms of psychotherapy 'out there', the shift from one to three is nonetheless a significant expansion, not least because it allows for comparison, conflict, consensus and dialogue. The other major difference between this work and Intimacies is methodological: whereas Bersani's approach is 'free-ranging' and 'accumulative' - weaving together a relationality from an array of diverse sources (in addition to the Phillipsian Psychoanalysis: a contemporary gay subculture, seventeenth century Catholic mysticism, and Plato's Phaedrus) - my approach is more sober and linear - a methodical thinking through of a relatively straightforward possibility. This methodological shift may be regarded as, I think, the natural progression from the inspirational stage of a project's inception, towards (although not yet 'to') the more pragmatic stage of its concrete implementation.

Lastly, it should be acknowledged that this paper builds not only on Foucault's 'call' and Bersani's resultant work but also on my own MA dissertation, which carries out a similar, parallel enquiry to the present one, but with a different set of practices.

\section{Three Listening Practices}

In this section, I introduce the listening practices under analysis in this paper. Because doing so in third-person narrative proves so overly cumbersome - with 'the listener', 'the speaker' and 'he or she' cluttering the text to the point of incomprehensibility second-person narrative will be used Given that the main purpose of the section is to give a 'sense' - a 'feel' - of the practices, as much as a technical understanding of them, this is perhaps not an unfortunate outcome. To a similar end, the practices are introduced before references to their authors and schools, so as not to let any prior intellectual or institutional loyalties compromise the 'experiential sampling' of the methods.

1. You are sitting with someone who is speaking to you. Ordinarily you might try to understand the person's meaning, or try to find something in your own experience that (you think) relates to what he/she is saying, but instead you do something different. Rather than listen for the content, for meaning, you listen for the words and sentences themselves: the syntax, the sentence structures. Listening in this way, irregularities in the person's speech leap out at you. For example: the person starts a sentence - 'I hate my-' - aborts it, then starts a new sentence - 'I mean, last Saturday I...' Because you are listening for this

\footnotetext{
${ }^{5}$ Ibid., 30.

${ }^{6}$ Ibid., 4.
} 
sort of thing, it is what strikes you, and you register your response by repeating the aborted sentence to the speaker: 'I hate my...' The speaker stops and fills in the nearly lost sentence: 'I hate my boss. I want to rip him to pieces.' Again, the content is largely irrelevant to you: it's perhaps the shortness of the sentences and the force of their enunciation that strike you now.

2. You are sitting with someone who is speaking to you. Ordinarily you might try to focus on what the person is saying, to grasp his or her meaning. But instead you do something different: you sit back and relax. More than that: you allow yourself to fall into a semi-conscious - semi-unconscious - state. You are barely aware of what the person is saying, or what is going on. Yet, in this relaxed, defocused, drifting state, you can sense, much more luminously than normal, an overall shape, or quality or feel to their being, in the cadences of their utterances, their gestures and so on. You continue to 'listen' in this way for around an hour, and at the end of it, the other gets up and leaves. You know nothing of what was said, and nothing of went on, but you feel moved, altered, reworked, redone.

3. You are sitting with someone who is speaking to you. Ordinarily, you might at the very least half-listen. On this occasion, however, you barely listen at all, keeping the person's monologue at the periphery of your awareness. Instead, you let your attention gather around what you feel. To begin with, you might notice only the feeling of the chair against your legs and back, the rise and fall of your chest, your heartbeat. Before long, though, a continuous field of feeling has emerged, full of minute detail. And, it is evident to you that the ongoing shape and fluctuations of that field is intimately connected to the state and state-fluctuations of the person you are with. In this, the person's utterances feature as just one facet of the person's overall 'body-mind' state. Over time, the person's breath deepens, their voice deepens, their speech gains character and conviction, and their body looks more vital - trembling and spasming slightly. Exactly an hour has passed.

\section{Critiques of Standard Communications}

The single most striking thing about the three practices, taken together, is that in each case, each in its own way, the listener aims not to understand the speaker's meaning. In other words, in all three cases, the normal position of meaning as central to communication is radically undermined.

This is no more wholly or explicitly the case than with the first practice, derived from Lacanian psychoanalysis as characterised by Bruce Fink. ${ }^{7}$ For Fink, following Lacan, the problem with meaning is that it is imaginary. ${ }^{8}$ This is meant in at least two senses: for the Lacanian, meaning is a closed system, utterly cut-off from the real

\footnotetext{
${ }^{7}$ Fink, Bruce. Against Understanding, Volume 1: Commentary and Critique in a Lacanian Key. (Hove: Routledge, 2014); Fink, Bruce. Against Understanding, Volume 2: Commentary and Critique in a Lacanian Key. (Hove: Routledge, 2014).

${ }^{8}$ Lacan, Jacques. Écrits. Trans. Bruce Fink. (London: W. W. Norton \& Company, 2002), 75-81; Fink, Against Understanding, Vol. 1, 9-11.
} 
world it supposedly represents. ${ }^{9}$ So meaning is imaginary in that the world it shows us is forever fictional - entirely removed from a reality we will never know. 'Understanding', moreover, is even more imaginary: not only do we imagine that we understand reality, but we imagine we know what another person means. ${ }^{10}$ For Fink, again following Lacan, the latter is even more implausible than the former: what I mean by a word or sentence can never be what you mean by it, and thus in 'understanding you' I am really only superimposing my meaning on you.

In the context of psychotherapy, we can see why listening for meaning may be ineffective and even counterproductive. If you, as therapist, can only ever understand me, as patient, in your own terms, your understanding of me can only ever amount to a re-appropriation - a conquest - of me. While Fink does argue this explicitly, ${ }^{11}$ there appears to be a flaw in that argument: if the analyst must translate the patient's speech, then surely the patient must in turn translate the analyst's translation - so that no such colonisation could, in fact, occur. One could, perhaps, still argue that even if the patient cannot grasp the analyst's meaning, perhaps (s)he can sense the disjuncture between what (s)he meant and what the analyst understood, and hence (futilely) seek to adopt the analyst's perspective, under the illusion that 'the expert knows best'. However, even that more elaborate argument is surplus to requirements: the bottom line is that meaning and reality do not meet and therefore real change in a person is unlikely to result from a change in understanding.

The criticism of meaning and understanding associated with the second listening practice bears resemblance to, yet significantly differs from Fink's. The practice is derived from the psychoanalytical method advanced and practiced by Christopher Bollas, $^{12}$ an analyst not associated with a particular psychoanalytical school. In Freudian psychoanalysis, the pivotal dualism of conscious/unconscious generates the sense of us humans living on the surface of a reality that has hidden (repressed) depths. In Lacanian psychoanalysis, we don't even live on the surface of reality: the real is elsewhere - we dwell in a world of meanings and symbols. The metapsychology of Christopher Bollas, now, lies somewhere in between: Bollas retains Freud's foregrounding of 'conscious/unconscious', rather than Lacan's 'imaginary/symbolic/real', yet Bollas has it that we reside not in consciousness, with the unconscious beneath, but that we dwell in the unconscious: we are more or less entirely unconscious beings. ${ }^{13} \mathrm{We}$ are dreaming constantly, subsumed in a thoughtworld of ideas, images, memories, and feelings that utterly shape our experience.

Bollas's metapsychology may sound like solipsism - 'the view that the self is all that exists or can be known' (OED) - but in fact it is far from that. For Bollas, unconsciousness is not obliviousness or 'a world of your own': it is an exquisite receptivity and responsiveness to the vast array of phenomena going on inside and outside of one's body. In fact, for Bollas, it is our (relative) consciousness that stifles us: the more we attempt to be conscious of what we think, the more we impede our profound thought-processes, and the less meaning-full we become:

\footnotetext{
${ }^{9}$ Ibid., 19-21.

${ }^{10}$ Ibid., 16-21.

${ }^{11}$ Ibid., 11.

${ }^{12}$ Bollas, Christopher. The Evocative Object World. Hove: Routledge, 2009; Bollas, Christopher. The

Infinite Question. Hove: Routledge, 2009.

${ }^{13}$ Bollas, The Infinite Question, 31-2.
} 
Although we do gain unconscious understandings of the movement of our analysand's unconscious life, such knowledge will only rarely enter our own consciousness. So as conscious beings, we are rather asleep. What we learn, we discover when we are not awake. ${ }^{14}$

When we focus 'consciously' on what we ourselves are thinking we don't get a chance to think. Likewise, when we focus consciously on what another is saying, we cannot receive it in a very rich way; we miss most of it. Thus, where for Fink, we cannot understand the other, for Bollas we can: but only, paradoxically, without our knowing it.

The third listening practice is from a method known as 'rooted talking', devised by Norwegian psychologist Gerda Boyesen, founder of Biodynamic Body Psychotherapy. ${ }^{15}$ Like other therapies under the umbrella of 'body psychotherapy', biodynamic therapists centralise the categorical dualism of 'mind/body' and argue that it is both conceptually flawed and organismically-damaging: when internalised mentally, it has a disembodying effect, whereby body is perceived as 'other than me', 'mine' and 'beneath me', and mind is perceived as 'me' and 'above the fleshly' separate, higher and superior. ${ }^{16}$ For body psychotherapists, then, a crucial task is the re-embodiment of the subject. ${ }^{17}$

Because mind and self are considered embodied, body psychotherapy practice can include physical and tactile methods, but likewise 'purely verbal' methods are treated as bodily events. In the case of rooted talking, the therapist focuses on his or her own body-state because this is taken as the best gauge of the other's body-state, of which their speech is considered but one facet. The implicit critique Boyesen's rooted talking makes, then, is that contemporary communicative practice is frequently disembodied: there is an over-focus (by both speaker and listener) on what the speaker is saying, and an under-focus on the overall context of speech as part of an ongoing overall somatopsychical process.

In sum, then: for Fink, meaning is imaginary and understanding impossible; for Bollas, meaning is only really meaningful when it stays unconscious; and for Boyesen meaning is only meaningful in a context in which feeling is primary.

\section{Dispute Between the Practices: A Question of Empathy}

While the last section was structured around a commonality between the practices their shared eschewal and criticism of meaning-centred listening - what also emerged were the differences between the practices and theories. However, while those differences are clearly not immaterial, they need not be taken necessarily as at odds with one another. The collective argument they make, or could make, is that a focus on meaning obscures other (arguably more valuable) dimensions of human intercourse, and that by not listening for meaning, you can 'hear' what the person is saying (and crucially 'hear' when they stop themselves saying something); and/or 'hear' (unconsciously) the unconscious multitude of what they are saying; and/or 'hear' what their body is doing (with your body), with and without their speech.

\footnotetext{
${ }^{14}$ Ibid.

${ }^{15}$ Boyesen, Gerda, Mona Lisa Boyesen. "Biodynamische Theorie und Praxis.” Die neuen Körpertherapien 1 (1977): 140-157.

${ }^{16}$ Reich, Wilhelm. The Function of the Orgasm. (London: Souvenir Press, 1983); Totton, Nick. Body Psychotherapy: An Introduction. (Maidenhead: Open University Press, 2003). 47-52).

17 Totton, Nick. Not a Tame Lion: Writings on therapy in its social political context. (Ross-on-Wye, 2012), 48-50.
} 
However, while it does seem possible to ally the three practices in such a way, that is not to say that the three are without conflict. On the contrary, there is a very prominent conflict between one perspective and the other two - a contestation of the concept of empathy.

For the Lacanian, language is more or less the entirety of human experience: everything that is perceived is perceived in terms of, well, terms. Thus, for the Lacanian, any notion of one person being able to directly 'receive'/'perceive' another's experience is out of the question: all experience and exchange is via the medium of language. Hence, for the Lacanian 'empathy' (here presented in the context of psychoanalysis) is as follows: '[Empathising analysts] strive to isolate a signifier in the patient's history or current experience that can also be found in their own'. ${ }^{18}$ And since what a signifier means to me is not what it means to you, and since in any case what you are saying is a whole host of polysemic signifiers, complexly arranged: 'This only leads them [empathising analysts] to "connive" with the patient' - i.e. to make out that they have understood. ${ }^{19}$

For Bollas and Boyesen, on the other hand, it is possible to 'sense' - to 'feel' another's experience, and for Bollas, expressly, this is what 'empathy' is based on: 'empathy $[\ldots]$ derives from feeling emotional qualities in the other. [...] One learns how to feel one's way into the other [...] to sense [in the context of psychoanalysis] the patient'. ${ }^{20}$ From a Lacanian position, this seems improbable - preposterous, even. How, exactly, is a feeling in one person sensible by another? Yet, with a shift of paradigm, it is the Lacanian view that comes to seem implausible. Cornell, for instance, states:

Human beings are continually engaged in interactions and communications that are not always fully conscious. All of us pick up, are influenced by, and utilize nonverbal signals from one another without knowing that we are doing so. Our physiological states of arousal and mood are sensitively regulated by the dynamics of our interpersonal fields. ${ }^{21}$

To put it more strongly still: if a human is, centrally, a being of senses - with sensory receptors spanning almost the entire human anatomy - then surely it is the idea that we wouldn't detect something of what a similar organism is feeling that is implausible?

\section{A Proposed Rapprochement Between the Practices}

Within psychotherapy, then, the question of whether it is possible to sense the feelings of others is a contentious issue. Since to settle the dispute decisively is beyond the scope of this paper, my proposal is that we accept the validity and efficacy of both sets of practices - i.e. those that fall on one side of the empathy debate (in this case, Lacan and Fink) and those that fall on the other (Bollas and Boyesen). Admittedly, this requires that we disregard the Lacanian objection just shown and its related thinking with it - namely around the exclusivity of language in human exchange - yet this rejection need not invalidate Lacanian analysis on the whole. That nonverbal,

\footnotetext{
${ }^{18}$ Fink, Against Understanding, Vol. 1, 76.

${ }^{19}$ Ibid.

${ }^{20}$ Bollas, The Evocative Object World, 41-42.

${ }^{21}$ Cornell, William F. "Nonconscious Processes and Self-Development: Key Concepts from Eric Berne and Christopher Bollas.” Transactional Analysis Journal 38 (2008): 202.
} 
subsymbolic, ${ }^{22}$ somatic and emotional intercourses are possible and that there are practices that amplify and utilise those currents for therapy, does not disqualify Lacanian practice; it merely adds other elements alongside it. And if we decide to substitute a place of equal - rather than total - primacy for language, alongside other modes of intercourse and exchange, then we need lose only a little of Lacanian theory.

\section{Effects of the Practices on 'The Individual'}

Having proposed a rapprochement that legitimises all three of the practices, I now consider the (purported) effects of each for the individual, before going on to consider possible wider applications of the practices.

When we focus on the wording more than the meaning of what another says, we can easily hear how his/her speech is punctuated. We can then draw out the aborted speech, or the hidden speech betrayed by a slip-of-the-tongue. ${ }^{23}$ In this way, the speaker is facilitated to speak (not understand) the full array of the things (s)he thinks, and thereby largely to become de-censored. ${ }^{24}$ This does not amount to selfunderstanding or self-development, but rather self-destabilising, -splitting, multiplying, -complexifying. ${ }^{25}$

When we do not focus on what a speaking person is saying at all, but rather defocus to the point of unconsciousness, while at the same time inviting the other into a similar state (i.e. 'please speak without consideration') we facilitate the other to communicate different, richer streams of thought than can happen in common conversation. ${ }^{26}$ Again, this does not amount to a strengthening of self, or to selfunderstanding, but on the contrary to a giving over of the self - to unconscious formations already in motion.

And when we do not really listen at all, but rather attend to what we as bodies are feeling, we find that our body-state is bound already - intrinsically - to the body-state of the other. And we find that by attending to our body-state, we become more 'incarnated' - we feel our thoughts as fleshly, our flesh as thoughtful. So (logically) as we change in this way, so do they: their gestures, voice and ideas become more substantial, vital and fluid. Again, the understanding and understood self is not bolstered in this: rather, it gives way in this instance to a sense of being that is fleshy, interactional and largely involuntary.

In sum: each of the three practices comprises a less deliberate, less self-conscious, less reflective kind of conversation, between a speaker who dissolves into/becomes/disperses out as his/her involuntary thoughts, and a listener who listens rather than 'understands'.

\footnotetext{
${ }^{22}$ Bucci, Wilma. Psychoanalysis and Cognitive Science: A Multiple Code Theory. (New York: The Guildford Press, 1997), 230-241.

${ }^{23}$ Fink, Against Understanding, Vol. 1, 15.

${ }^{24}$ Ibid.

${ }^{25}$ Ibid., 7-8.

${ }^{26}$ Bollas, The Infinite Question, 19-23.
} 


\section{Potential Effects of the Practices on Society}

Why might (a) Society want to disperse or absorb self in the sorts of ways just described? Leo Bersani indicates why in Intimacies:

The imaginary spaces in which they [personal and national identities] are enclosed create equally imaginary yet powerfully operative borders outside of which lies everything that is essentially different from them. [...] Because [they] are by nature settled or congealed differences, they are inclined to define themselves, indeed to construct the unity of their being, in terms of an aggressively defensive posture toward the differences outside their identitarian frontiers. ${ }^{27}$

Meaning is 'imaginary yet powerfully operative': and so, if I put a great deal of stock in meaning, and the meaning-field in which I exist is one in which I am one thing e.g. 'white', 'male', 'Western', 'Christian' - and you are my opposite - 'dark', 'female', 'Eastern', 'Muslim' - then I am doomed to fear you, as alien and opposed to me; I am condemned, by definition, to be at war with you.

But the imaginary differences that divide us so categorically can only retain their operative power insofar as we deny their constructedness. The circulation and frequent practice of communication-forms that show us, palpably, the arbitrariness of those categories, and the pleasures that open up when we loosen our understandings, may decisively derail that power.

More striking, perhaps, than anything else throughout this study, has been the overpowering sense of an iron grip that meaning has - but need not have - on our human relations. While one may learn a 'new relational mode' in 'private practice', with a formally consenting other, it seems another thing entirely to extend that into everyday life. There appears to be a widespread 'resistance to meaning-loss' that, especially from the perspective of other intercourses, feels like an oppressive monopoly, and which makes alternative intercourse feel all the more imperative.

The solution Bersani ultimately proposes is a new kind of love-relationship based on sameness. While something as powerfully binding as 'love' may be needed to forge a substantially different (and hopefully less intrinsically violent) society, the dissolving of existing bonds through the spread of practices (to habits) that expose the imaginariness of our identities, may be a good start.

\section{Conclusion}

In conclusion, I have argued that our relationalities and relations are more meaningcentred than they could or ought to be. By limiting ourselves to speaking and listening practices that focus on meaning, we easily mistake the imaginary for the real. The meaning of our imaginary, moreover, is made up of opposed and hierarchical binaries - higher/lower, white/black, body/mind, man/woman - that set us at odds with each other. But listening and speaking practices need not always revolve around meaning and by introducing and routinizing new non-meaning-centred practices, we may finally lose the loyalties that embattle us.

\footnotetext{
${ }^{27}$ Bersani and Phillips, Intimacies, 85 .
} 


\section{Bibliography}

Bersani, Leo and Adam Phillips. Intimacies. Chicago: University of Chicago Press, 2008.

Bollas, Christopher. The Evocative Object World. Hove: Routledge, 2009.

The Infinite Question. Hove: Routledge, 2009.

Boyesen, Gerda, Mona Lisa Boyesen. "Biodynamische Theorie und Praxis." Die neuen Körpertherapien 1 (1977): 140-157.

Bucci, Wilma. Psychoanalysis and Cognitive Science: A Multiple Code Theory. New York: The Guildford Press, 1997.

Cornell, William F. "Nonconscious Processes and Self-Development: Key Concepts from Eric Berne and Christopher Bollas.” Transactional Analysis Journal 38 (2008): 200-217.

Fink, Bruce. Against Understanding, Volume 1: Commentary and Critique in a Lacanian Key. Hove: Routledge, 2014.

--------- Against Understanding, Volume 2: Cases and Commentary in a Lacanian Key. Hove: Routledge, 2014.

Foucault, Michel. "Friendship as a Way of Life." In Foucault Live: Collected Interviews, 1961-1984, edited by Sylvère Lotringer, translated by Lysa Hochroth and John Johnson, 308-312. New York: Semiotext(e), 1996

Lacan, Jacques. Écrits, translated by Bruce Fink. London: W. W. Norton \& Company, 2002.

Reich, Wilhelm. The Function of the Orgasm. London: Souvenir Press, 1983.

Totton, Nick. Body Psychotherapy: An Introduction. Maidenhead: Open University Press, 2003.

Not a Tame Lion: Writings on therapy in its social political context. Ross-on-Wye, 2012. 